\title{
PECULIAR PROPERTIES OF THE PLANT TAXONOMY AT THE HERBARIUM MUSEUM DEPARTMENT PHARMACEUTICAL AND NATURAL SCIENCES FIRST MOSCOW STATE MEDICAL UNIVERSITY NAMED AFTER SECHENOV
}

\author{
SAMYLINA IA, ERMAKOVA VA, STRELIAEVA AV, KARTASHOVA NV* \\ Department of Pharmaceutical and Natural Sciences, Sechenov First Moscow State Medical University, Moscow, Russia. \\ Email: nataliekartashova@gmail.com
}

Received: 29 June 2018, Revised and Accepted: 03 December 2018

\section{ABSTRACT}

Objective: Department of Pharmaceutical and Natural Sciences of Sechenov First Moscow State Medical University offers students herbarium which should be attributed to special herbaria, namely the collection contains medicinal plants that are well known as official medicine and are widely used in folk medicine. The herbarium provides samples of medicinal plants for the formation of knowledge, practical skills of students of the pharmaceutical faculty. More than 7000 copies of herbarium sheets are offered for the work of students.

Methods: Herbarium samples were identified and selected according to the engage thematic plan: Medicinal plants containing essential oils, cardiac glycosides, saponins, polysaccharides, phenolic glycosides, coumarins, lignans, flavonoids, tannins, anthracene derivatives, vitamins, fatty oils, and different groups of biologically active substances. In addition, the department made a small collection of the rare herbarium, which presents medicinal plants widely used in homeopathy, which is used for conducting elective discipline. The wide research of different branches of the medicinal plan was made with the help of pharmacognosy department. The study was carried out with an objective to estimate the need for each herbarium by topic

Results: The herbarium fund was formed by the staff of the pharmacognosy department for many years on the basis of the approved pharmacognosy program. The collection is used for research by students - to perform diploma, qualifying works, and teachers to prepare teaching aids, and pharmacopeia articles develop and conduct research. The number of herbarium specimens is stored in the main fund - more than 5000.240 species of medicinal plants belonging to 104 families are represented.

Keywords: Herbarium, Essential oils, Cardiac glycosides, Saponins, Polysaccharides, Phenolic glycosides, Coumarins, Lignans, Flavonoids, Tannins, Anthracene derivatives, Vitamins, Fatty oils.

(C) 2019 The Authors. Published by Innovare Academic Sciences Pvt Ltd. This is an open access article under the CC BY license (http://creativecommons. org/licenses/by/4. 0/) DOI: http://dx.doi.org/10.22159/ajpcr.2019.v12i4.28196

\section{INTRODUCTION}

The word "herbarium" originally referred to the book about medicinal plants. Tournefort (circa 1700) used this term to refer to the collection of dry plants; He was adopted by Linnaeus and under his influence replaced the earlier term "hortus siccus" with "herbarium." Now herbarium is also called the collection of dried (or otherwise fixed) plants and the institution in which it is stored $[1,2]$.

Herbarium at its creation solves the following tasks:

- Stores reference material;

- Provides samples for determination by a comparative method;

- Serves as a standard of correct scientific names.

Depending on the tasks and opportunities, as well as the nature of the work carried out, it is possible to single out herbariums common, regional, local, and special. Common herbarium can be very large. The largest herbarium of our country and one of the largest in the world is stored in the Botanical Institute, V.L. Komarov in St. Petersburg. It has more than 5 million sheets of plants found throughout Russia and neighboring countries. Herbarium of K. Linnaeus and Kew Botanical Garden in London has 6.5 million specimens [3].

However, there are small herbaria that study the flora of a region or region. Each higher educational institution, which prepares pharmacists, biologists, ecologists usually has its herbarium collections with certain requirements. Educational herbariums belong to special herbaria.

\section{HERBARIUM USED IN SECHENOV FIRST MOSCOW STATE MEDICAL} UNIVERSITY

Department of Pharmaceutical and Natural Sciences, Sechenov First Moscow State Medical University, offers students for training her herbarium. Undoubtedly, this herbarium should be attributed to special herbaria, namely the collection contains medicinal plants that are well known as official medicine and are used in folk medicine. The established task, which is solved by the herbarium of the pharmacognosy department, is to provide samples of medicinal plants for the formation of knowledge, practical skills of students of the pharmaceutical faculty. After all, more than $50 \%$ of drugs and food additives that form the assortment of a modern pharmacy account for medicinal plants or substances derived from medicinal plants

More than 7000 copies of herbarium sheets are offered for the work of students. A herbarium of two types is used to teach students - training herbarium and Examination herbarium. Each sheet school herbarium contains a sample not only medicinal plant but also raw materials, which are harvested from this plant and be sure to label the Latin and Russian names of medicinal plants, family, place, and year of harvesting, surname, name, and patronymic of the student and the teacher have prepared and determined the herbarium. This herbarium is offered to the student in the class. A specific task and a sample of raw materials harvested from this plant type are attached to it. In the lesson, lasting 4 academic $\mathrm{h}$, the student gets acquainted with 5-15 herbarium specimens of medicinal plants. At the end of the session, the student should be able to recognize a medicinal plant, called by its Latin, Russian name, Latin and Russian family name, and Latin and Russian 
Table 1: Department of pharmaceutical and natural sciences of Sechenov First Moscow State Medical University

\begin{tabular}{|c|c|c|c|c|}
\hline Department & Number of storage units & Number of species & Number of series & Number of families \\
\hline General department & 5663 & 240 & 146 & 104 \\
\hline Exchange department & 800 & & & \\
\hline Rare department & 652 & 163 & & \\
\hline Demonstration all collection & 143 & 139 & 120 & 59 \\
\hline \multicolumn{5}{|l|}{ General department, herbarium classified by topic } \\
\hline Essential oils & 1568 & 45 & 35 & 17 \\
\hline Cardiac glycosides & 250 & 15 & 9 & 9 \\
\hline Saponins & 288 & 13 & 9 & 7 \\
\hline Polysaccharides & 605 & 21 & 7 & 6 \\
\hline Tannins & 531 & 19 & 11 & 7 \\
\hline Anthracene derivatives & 194 & 7 & 7 & 5 \\
\hline Alkaloids & 616 & 33 & 29 & 16 \\
\hline Vitamins & 614 & 19 & 11 & 9 \\
\hline Different groups of biologically active substances & 63 & 3 & 3 & 3 \\
\hline Fatty oils & 128 & 7 & 7 & 6 \\
\hline Phenolic glycosides & 476 & 33 & 18 & 10 \\
\hline Coumarins & 251 & 12 & 9 & 9 \\
\hline
\end{tabular}

names of raw material which is procured from this type of medicinal plants. To characterize the chemical composition of raw materials, to name the medicines and the pharmacological group to which they refer. To control students' knowledge, exam samples of herbarium are used, which, unlike the educational herbarium, do not contain labels.

Herbarium samples selected according to the engage thematic plan: Medicinal plants containing essential oils, cardiac glycosides, saponins, polysaccharides, phenolic glycosides, coumarins, lignans, flavonoids, tannins, anthracene derivatives, vitamins, fatty oils, and different groups of biologically active substances. In addition, the department has a small collection of the rare herbarium, which presents medicinal plants widely used in homeopathy, which is used for conducting elective discipline. Collection of rare herbarium is used for research by students - to perform diploma, qualifying works and teachers to prepare teaching aids, and pharmacopeia articles develop and conduct research. The largest number of herbarium specimens is stored in the main fund - more than 5000. 240 species of medicinal plants belonging to 104 families are represented.

The most commonly used in the educational process are medicinal plants belonging to the families: Asteraceae, Liliaceae, Lamiaceae, Rosaceae, Araliaceae, Fabaceae, Solanaceae, Papaveraceae, Apocynaceae, Ranunculaceae, and others.

The herbarium fund was formed by the staff of the pharmacognosy department for many years on the basis of the approved pharmacognosy program. Depending on the program change, the assortment of herbarium stock also changed. The primary task of the department was to equip the educational process with $100 \%$ of the species of medicinal plants included in the program. Since the visibility of learning plays a huge role in the formation of deep basic knowledge of the subject, every medicinal plant proposed for studying the student must have a herbarium equivalent. At the moment, the need for the pharmacognosy department in herbarium specimens is $98 \%$ complete. However, some types of herbaria are presented in 4-5 copies, which cause inconvenience and labor costs for laboratory assistants and teacherscurators. Simultaneously, the chair conducts classes in six groups. Therefore, it is advisable to have at least six prepared sets of herbariums for each topic, and at least a few kits for out-of-class preparation of students in extra time. Separate sets for a day, part-time, and evening department are needed. The question is raised about the formation of kits for testing. Proceeding from the foregoing, the need for herbarium samples sharply increases to 9600 samples (Table 1).

Need for herbarium by topic:

1. Medicinal plants containing essential oils

2. Medicinal plants containing cardiac glycosides
3. Medicinal plants containing saponins

4. Medicinal plants containing polysaccharides

5. Medicinal plants containing tannins

6. Medicinal plants containing anthracene derivatives

7. Medicinal plants containing alkaloids

8. Medicinal plants containing vitamins

9. Medicinal plants of different biological effect

10. Medicinal plants containing fatty oils

11. Medicinal plants containing flavonoids

12. Medicinal plants containing phenolic glycosides, coumarins, and chromones.

We embarrassed ourselves feel when at lectures, laboratory and practical training, in practice, with students in the botanical gardens, says "London is world famous herbarium of Linnaeus, the herbarium of de Candolle and Boissier in Geneva, the Herbarium of Moscow State University and give assignments to students fabricate fresh grass herbarium yarrow, mint, thigh highs." In our textbooks and manuals, we have to write, for example, "leaves and flowers of purple. Herbarium or caption in the training manual Adonis vernalis Herbarium." Moreover, grandiose monuments, of many generations of different countries and peoples, where millions of sheets of plants are stored, are also called the herbarium. For the first time, we offer similar educational facilities at medical faculties of medical universities, academies, institutes, and call audiences the museums herbariums. Is this proposal legitimate? We bring to the public discussion. We give the rationale for our proposal.

Museology is a scientific discipline that studies the origin of museums, their societies, functions, issues of theory and methodology of museum work. Museums - research, scientific and educational institutions, engaged in packaging, storage, study and popularization of monuments, history, material and spiritual culture - first-hand knowledge about the development of nature and human society $[4,5]$. In science, there is a concept - a biological museum; therefore, it is correct to have - a herbarium museum. Therefore, writing of also justified, for example, peppermint herbarium, herbarium lily, and herbarium digitalis purpurea.

\section{ACKNOWLEDGMENT}

The authors would like to grateful to the Department of Pharmaceutical and Natural Sciences, Sechenov First Moscow State Medical University, for providing infrastructure and instrumentation facilities.

\section{AUTHORS' CONTRIBUTIONS}

V.A. Ermakova and A.V. Strelyaeva conceived of the presented idea. A.V. Strelyaeva developed the theory and performed the computations. N.V. 
Kartashova and I.A Samylina collected the materials for the article. All authors discussed the results and contributed to the final manuscript. N.V. Kartashova wrote the manuscript with support from A.V. Strelyaeva.

\section{CONFLICTS OF INTEREST}

We have no conflicts of interest to declare.

\section{REFERENCES}

1. Sozinov O, Buyak AV. Herbarium of the Grodno State University: The First Results. Problems of Developing Botanical Database: Abstracts of the Meeting (Novosibirsk, October 24-26, 2000). Moscow: Patent; 2000. p. 72-3.

2. Sozinov O, Buyak AV. Database "Herbarium of Vascular Plants of the
Grodno State University Named After Kupala Y". Botanical Gardens: State and Perspective of Conservation, Study, use of the Biological Diversity of the Plant World: Tez document International Science Conference. Central Botanical Garden of the National Academy of Sciences of Belarus. Minneapolis: BSPU; 2002. p. 261-2.

3. Khusnulina TR. Available from: https://www.redaktor@sgu.ru., herbarium sarat@mail.ru.2010.

4. Jaafar NS, Hamad MN, Abbas IS, Jaafar IS. Qualitative phytochemical comparsion between flavonoids and phenolic acids contents of leaves and fruits of Melia azedarach (Family: Meliaceae) cultivated in Iraq by HPLC and HPTLC. Int J Pharm Pharm Sci 2016;8:242-50.

5. Muchtaridi M, Suryani D, Qosim WA, Saptarini N. Quantitative analysis of $\alpha$-mangostin inmangosteen (Garcinia mangostana L.) Pericarp extracts from four districts of west java by HPLC method. Int J Pharm Pharm Sci 2016;8:232-6. 